\title{
A case of prostate cancer revealed by erythroderma
}

\author{
Samia Mrabat ${ }^{1}$, Sara Elloudi', Hanane Baybay', Zakia Douhi', Fatima Zahra Mernissi', \\ Soufiane Ennaciri ${ }^{2}$, Othmane Chama ${ }^{2}$, Mustapha Ahsaini ${ }^{2}$, Soufiane Mellas ${ }^{2}$, \\ Jalaleddine El Ammari ${ }^{2}$, Med Fadl Tazi' ${ }^{2}$, Med Jamal El Fassi' ${ }^{2}$, Moulay Hassan Farih ${ }^{2}$
}

\author{
${ }^{1}$ Department of Dermatology, University Hospital Hassan II, Fes, Morocco, ${ }^{2}$ Department of Urology, University Hospital \\ Hassan II, Fes, Morocco
}

Corresponding author: Dr. Samia Mrabat, E-mail: samiamrabat91@gmail.com

Sir,

Paraneoplastic cutaneous disorders (PCDs) are skin conditions associated with internal malignancies but that are not malignant themselves [1]. There are numerous skin diseases categorized as PCDs, such as dermatomyositis, bullous dermatosis, erythroderma, prurigo, lichen planus, and porokeratosis. Most importantly, there are no malignant cells infiltrating into the skin lesions of PCDs [2].

A 79-year-old man presented to our dermatology department with a generalized rash persistent for the last two months and importantly associated with itching. The patient had no history of drug allergy or a past dermatological condition. A clinical examination showed a generalized erythematous rash with scaling (Fig. 1). A skin biopsy revealed acanthosis and parakeratosis, but found no cause for the rash. The patient was treated with potent topical steroids and antihistamines but with no relief. Given the patient's complaint of dysuria and frequent urination, we measured the level of prostatespecific antigen (PSA) to find it abnormally high, at 45. A CT scan revealed iliac lymph node metastases. Prostate MRI revealed a suspicious lesion in the central area, corresponding to prostate cancer (Fig. 2). A prostate biopsy confirmed the diagnosis of adenocarcinoma classified as Gleason $8(4+4)$. The patient was put under hormone therapy and radiation therapy. Two months after beginning the treatment, the patient achieved remission of the rash, but the itching remained unaffected.

Erythroderma is a complex multifactorial dermatosis, whose prognosis depends on the causative agent. Despite the fact that it rarely appears as a paraneoplastic

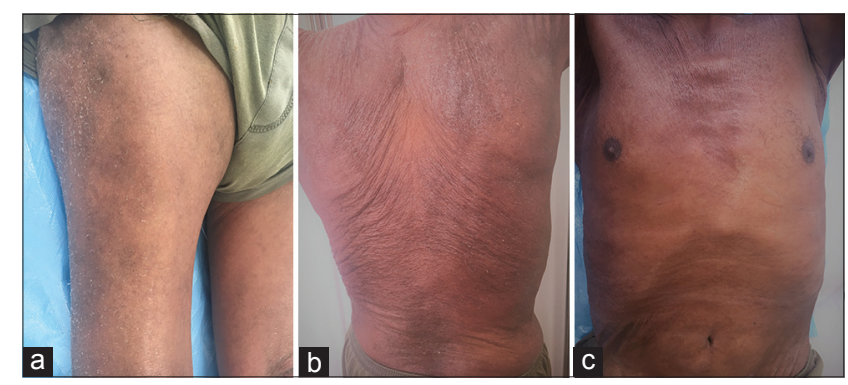

Figure 1: (a-c) Generalized erythematous rash of the trunk and extremities.

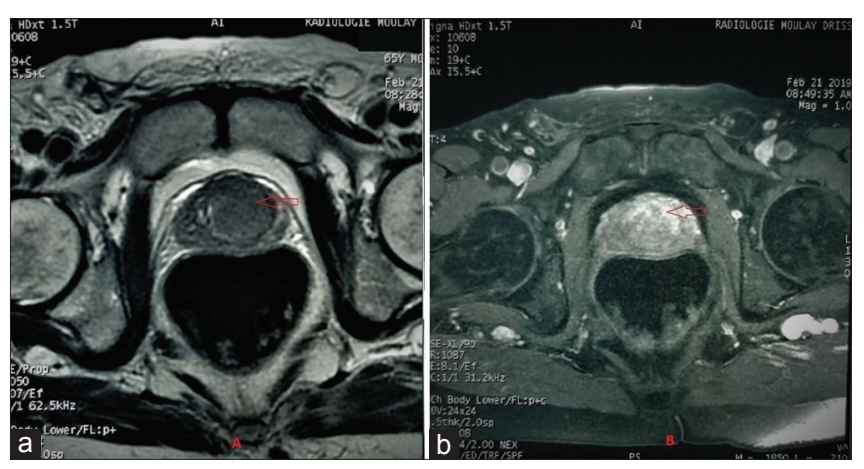

Figure 2: Cross sections of prostate MRI; a T2 sequence (a) and a dynamic injected sequence (b) showing a suspicious lesion in the central area, corresponding to prostate cancer.

syndrome, a clinical finding of a rapidly extending erythema along with various degrees of scaling, especially in a patient without previous dermatological disorders, should prompt further investigation for underlying malignancies, as in this extremely rare case of erythroderma associated with prostate cancer.

\section{Consent}

The examination of the patient was conducted according to the principles of the Declaration of Helsinki.

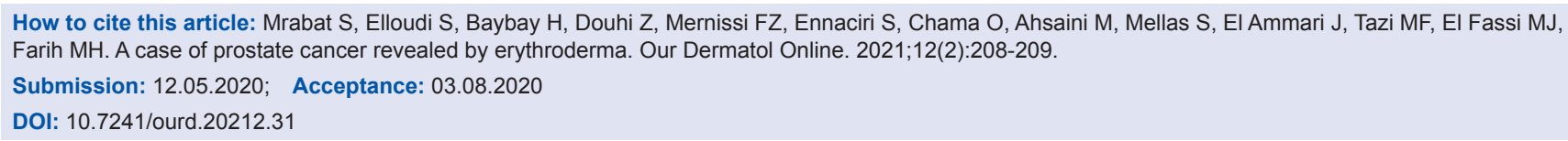


The authors certify that they have obtained all appropriate patient consent forms, in which the patients gave their consent for images and other clinical information to be included in the journal. The patients understand that their names and initials will not be published and due effort will be made to conceal their identity, but that anonymity cannot be guaranteed.

\section{REFERENCES}

1. Hanafusa T, Igawa K, Takagawa S, Harada J, Tani M, Sawada Y, et al. Erythroderma as a paraneoplastic cutaneous disorder in systemic anaplastic large cell lymphoma. J Eur Acad Dermatol Venereol. 2012;26:710-3.

2. Chung VQ, Moschella SL, Zembowicz A, Liu V. Clinical and pathologic findings of paraneoplastic dermatoses. J Am Acad Dermatol. 2006;54:745-62.

Copyright by Samia Mrabat, et al. This is an open-access article distributed under the terms of the Creative Commons Attribution License, which permits unrestricted use, distribution, and reproduction in any medium, provided the original author and source are credited.

Source of Support: Nil, Conflict of Interest: None declared. 